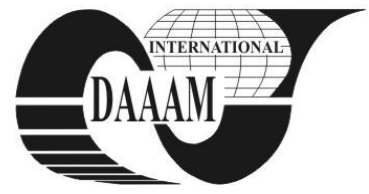

Annals of DAAAM for 2011 \& Proceedings of the 22nd International DAAAM Symposium, Volume 22, No. 1, ISSN 1726-9679 ISBN 978-3-901509-83-4, Editor B. Katalinic, Published by DAAAM International, Vienna, Austria, EU, 2011 Make Harmony between Technology and Nature, and Your Mind will Fly Free as a Bird Annals \& Proceedings of DAAAM International 2011

\title{
MEASUREMENT UNCERTAINTY IN PROCESS OF LINE SCALES CALIBRATING
}

\author{
RUNJE, B[iserka] \& MEDIC, S[rdjan]
}

\begin{abstract}
The paper presents main characteristics of the device for calibration of line scales and measurement uncertainty evaluation by GUM and MCS method. As a part of research on the impact of measurement uncertainty the following was investigated: the position of laser light sources and optical components, minimizing Abbe's error (Bosse at al. 2007), the determination of the middle line of line scales, alignment of line scale and laser beam, straightness movement of table, pitch, roll and yaw angles, environmental conditions affect the laser wavelength and the geometry of device and the impact of losing focus while moving of table. Measurement uncertainty evaluation has been validated in comparison measuremens EURAMET Key Comparison, EURAMET.L-K7 "Calibration of line scales"

Key words: measurement uncertainty, line scale, length
\end{abstract}

\section{INTRODUCTION}

The Laboratory for Precise Measurement of Length, which is at the same time the National Laboratory for Length (in text 'Laboratory') takes part in CIPM MRA comparisons of length standards, which include line scales as very important standards of length. Calibration of the line scales at the level of measurement uncertainties of the order of value $U=0,1 \mu \mathrm{m}, k=$ 2. $P=95 \%$ represents today still a world problem, although these levels of measurement uncertainties are necessary in the context of ensuring the traceability. So, the Laboratory started to design their own optoelectronic system for the calibration of line scales.

\section{MEASUREMENT DEVICE FOR CALIBRATING OF LINE SCALES}

The measuring range of the device is $800 \mathrm{~mm}$ and it is primarily intended for the calibration of line scales. The sighting process is done by means of a microscope with a digital CCD camera Olympus DP 70 with 12, 5 Megapixels. The microscope is fitted with lens of different magnification (10X, 20X, 50X). The lenses are selected in compliance with the object of measurement.

The measuring system used is the laser interferometer (Reinshaw ML 10). The basis of the Renishaw Laser Interferometer system is He-Ne Laser operating at a wavelength of $0,663 \mu \mathrm{m}$. Measurement device for calibrating of line scales is presented in Figure 1. In order to achieve order in the abovementioned measurement uncertainties, it is necessary to use software in the process of detecting the line centre of the measuring scale in reference to requirement limits (Beers and Penzes,1999) The software solution functions in such a way that all the pixels of a certain image are transmitted into a black\&white combination and then the position of the line centre is calculated by arithmetic algorithms (Družovec at.al. 2009).
The software solution provides the exact position of the line centre in pixels. In order to convert the values in pixels into the length values, it is necessary to calibrate the pixels size, i.e. to find out the length value of every pixel.

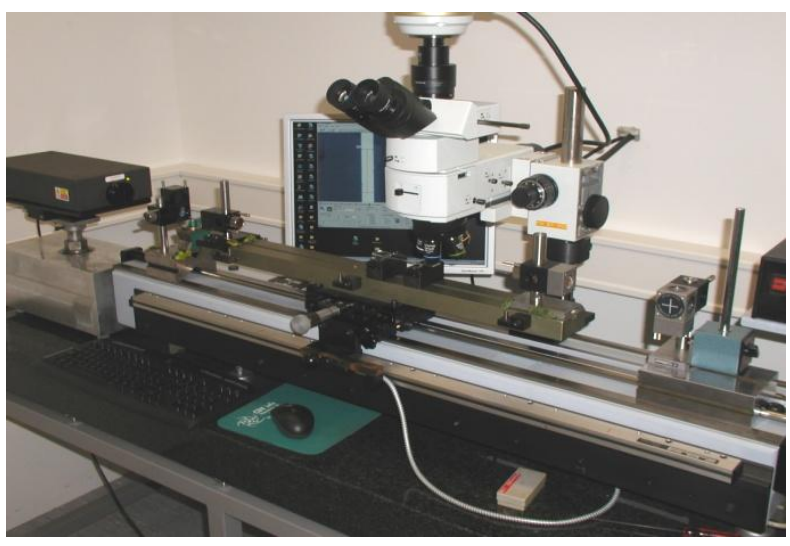

Fig. 1. Calibration system for precise measuring scales

\section{CALCULATION OF THE MEASUREMENT UNCERTAINTY BY APPLYING GUM AND MCS METHOD}

The mathematical model of measurement has been given by expression (1):

$$
\begin{aligned}
& L_{M S}=\left(N_{2}-N_{1}\right) \frac{\lambda}{2 n_{\text {air }}}-\left(\delta l_{n 2}-\delta l_{n 1}\right)+\delta l_{D P}+\delta l_{l i}+\delta l_{A z}+\delta l_{A y}+L \cdot \alpha_{s} \cdot \Delta t_{s} \\
& +\delta l_{s h}+\delta l_{s V}+\delta l_{a i}+\delta E_{a l g}+\delta e_{\text {tok }}+\delta l_{o p t}+\delta l_{s E}
\end{aligned}
$$

where:

$N_{i} \quad$ - Number of wavelengths

$\lambda$ - Laser wavelength

$n_{\text {air }}{ }^{-}$- Refractive index of air

$\delta l_{n i} \quad$ - Interferometer nonlinearity

$\delta l_{D P}$ - Deadpath influence

$\delta l_{l i} \quad$ - Interferometer cosine error

$\delta l_{A z} \quad$ - Abbe offset in $\mathrm{z}$ and pitch

$\delta l_{A y} \quad$ - Abbe offset in y and yaw

$L \quad$ - Nominal length of line scale

$\alpha_{s} \quad$ - Thermal exp. Coeficient

$\Delta t_{s}$ - Deviation scale temperature from $20{ }^{\circ} \mathrm{C}$

$\delta l_{s h} \quad$ - Scale alignement horizontaly

$\delta l_{s v^{-}}$- Scale alignement verticaly

$\delta l_{a i} \quad$ - Scale support influence

$\delta E_{a l g}$ - Line quality influence

$\delta e_{f o k}$ - Focus loosing influence

$\delta l_{\text {opt }}$ - Uncertainty of measurement optics due to temp. dev.

$\delta l_{s E} \quad$ - Reproducibility of line detection

The yields of components of the standard uncertainty for the line scale of $100 \mathrm{~mm}$ are presented in Table 1 . 


\begin{tabular}{|c|c|c|c|c|}
\hline $\begin{array}{c}\text { Source an d Component } \\
\text { of } \\
\text { Uncertainty, } x_{i}\end{array}$ & Distr. & $\begin{array}{l}\text { Amount } \\
\text { of } \\
\text { Stand. } \\
\text { uncertaint } \\
\text { у } u\left(x_{i}\right)\end{array}$ & $c_{i}=\partial d L / \partial x_{i}$ & $\begin{array}{c}\text { Yield to } \\
\text { measure. } \\
\text { uncertainty, } \\
\mathrm{nm}, \mathrm{L} \text { in } \mathrm{mm}\end{array}$ \\
\hline $\begin{array}{l}\text { Abbe offset in } \mathrm{z} \text { and } \\
\text { pitch, } \delta l \mathrm{Az}\end{array}$ & $\mathrm{R}$ & $16,8 \mathrm{~nm}$ & 1 & 16,8 \\
\hline $\begin{array}{l}\text { Abbe offset in y and } \\
\text { yaw, } \delta l_{A y}\end{array}$ & $\mathrm{R}$ & $4,3 \mathrm{~nm}$ & 1 & 4,3 \\
\hline Laser wavelength, $\delta \lambda$ & $\mathrm{R}$ & 0,03 & L & $0,03 \mathrm{~L}$ \\
\hline Air temperature, tair & $\mathrm{R}$ & $0,12^{\circ} \mathrm{C}$ & $9,5 \cdot 10^{-7} \mathrm{~L} /{ }^{\circ} \mathrm{C}$ & $0,112 \cdot \mathrm{L}$ \\
\hline Air pressure, pair & $\mathrm{R}$ & $13 \mathrm{~Pa}$ & $2,7 \cdot 10^{-7} \mathrm{~L} / \mathrm{Pa}$ & $0,035 \cdot \mathrm{L}$ \\
\hline Relative humidity, RHair & $\mathrm{R}$ & 0,06 & $8,5 \cdot 10^{-7} \mathrm{~L}$ & $0,050 \cdot \mathrm{L}$ \\
\hline 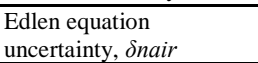 & $\mathrm{N}$ & $2 \cdot 10^{-8}$ & $\mathrm{~L}$ & $0,020 \cdot \mathrm{L}$ \\
\hline Deadpath, $\delta l D P$ & $\mathrm{R}$ & $1,8 \mathrm{~nm}$ & 1 & 1,8 \\
\hline $\begin{array}{l}\text { Interferometer } \\
\text { nonlinearity, } \delta l N L\end{array}$ & $\mathrm{U}$ & $3 \mathrm{~nm}$ & 1 & 3 \\
\hline $\begin{array}{l}\text { Interferometer cosine } \\
\text { error, } \delta l_{l i}\end{array}$ & $\mathrm{R}$ & $0,48 \mathrm{~L}$ & 1 & $0,48 \cdot \mathrm{L}$ \\
\hline $\begin{array}{l}\text { Deviation scale } \\
\text { temperature from } 20^{\circ} \mathrm{C} \text {, } \\
\Delta t s\end{array}$ & $\mathrm{~N}$ & $0,12^{\circ} \mathrm{C}$ & $5 \cdot 10^{-7} \mathrm{~L} / \mathrm{K}$ & $0,06 \cdot \mathrm{L}$ \\
\hline $\begin{array}{l}\text { Thermal exp. Coef., } \alpha_{s,} \\
\mathrm{~K}^{-1}\end{array}$ & $\mathrm{R}$ & $0,289 \cdot 10^{-7}$ & $\mathrm{~L} \cdot 0,5 \mathrm{~K}$ & $0,0145 \cdot \mathrm{L}$ \\
\hline $\begin{array}{l}\text { Scale alignement hor., } \\
\delta l S h\end{array}$ & $\mathrm{R}$ & $0,001 \mathrm{~L}$ & 1 & $0,001 \cdot \mathrm{L}$ \\
\hline $\begin{array}{l}\text { Scale alignement vert, } \\
\delta l S V\end{array}$ & $\mathrm{R}$ & $0,0023 \mathrm{~L}$ & 1 & $0,0023 \cdot \mathrm{L}$ \\
\hline Scale support, dlai & $\mathrm{R}$ & $0,0058 \mathrm{~L}$ & 1 & $0,0058 \cdot \mathrm{L}$ \\
\hline Line quality, $\delta$ Ealg & $\mathrm{N}$ & $6,4 \mathrm{~nm}$ & 1 & 6,4 \\
\hline Focus loosing, defok & $\mathrm{N}$ & $18 \mathrm{~nm}$ & 1 & 18 \\
\hline $\begin{array}{l}\text { Measurement optics, } \\
\text { Slopt }\end{array}$ & $\mathrm{R}$ & $58 \mathrm{~nm}$ & 1 & 58 \\
\hline $\begin{array}{l}\text { Interferometer } \\
\text { resolution, } N\end{array}$ & $\mathrm{R}$ & 0,003 & $\lambda / 2$ & 1 \\
\hline $\begin{array}{l}\text { Reproducibility of line } \\
\text { detection, } \delta l S E\end{array}$ & $\mathrm{~N}$ & $11,6 \mathrm{~nm}$ & 1 & 11,6 \\
\hline \multicolumn{3}{|l|}{ Combined variance } & \multicolumn{2}{|c|}{$\begin{array}{c}u^{2}=\left(65^{2}+0,5^{2} \cdot L^{2}\right) \mathrm{nm}, L \text { in } \\
\mathrm{mm}\end{array}$} \\
\hline \multicolumn{3}{|c|}{$\begin{array}{l}\text { Linearised expanded measurement } \\
\text { uncertainty } U, P=95 \%, k=2\end{array}$} & \multicolumn{2}{|c|}{$\begin{array}{c}U=(130+0,66 \cdot L) \mathrm{nm}, L \text { in } \\
\mathrm{mm}\end{array}$} \\
\hline
\end{tabular}

Tab. 1. Yields of components of standard uncertainty, and sources of uncertainty

Calculation of the measurement uncertainty (validation) has also been performed, by means of MCS method (JCGM 101:2008.) Probability density function of the output value has been obtained by $M=100000$ simulations. The probability density function $g\left(x_{i}\right)$ has been simulated by the MCS method based on the expression (1). Figures 2 and 3 show the probability density functions of the output value $L_{M S}$ where the distance between spots of reference and reflected beams are $\mathrm{s}=$ $2 \mathrm{~mm}$ and $\mathrm{s}=5 \mathrm{~mm}$ respectively.

While the GUM method assumes normal distribution of the output value, the MCS method yielded experimental distribution of the output value that may more or less match the assumed normal distribution. The form of the experimental curve will depend primarily on the probability density function of the most significant input value (Medic et al., 2003).

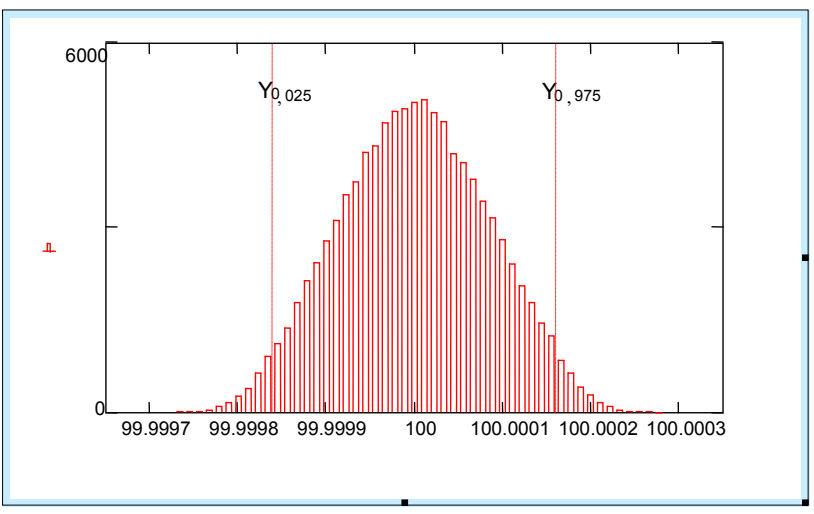

Fig. 2. Probability density function $g\left(L_{M S}\right)$ where $s=2 \mathrm{~mm}$

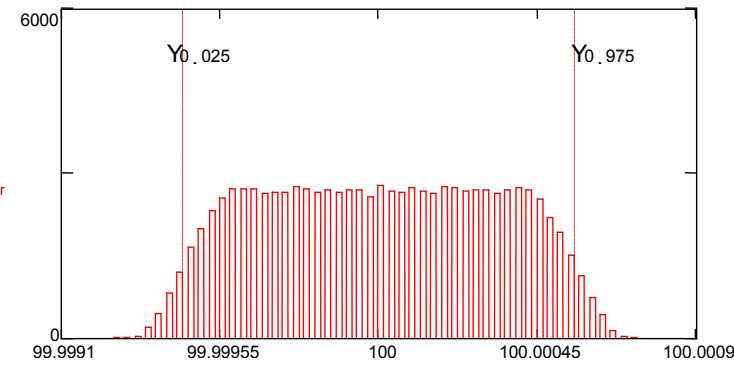

Fig. 3. Probability density function $g\left(L_{M S}\right)$ where $s=5 \mathrm{~mm}$

In this case, due to the dominant influence of interferometer cosine error (Quenelle, 1983.) on the measurement uncertainty, the normal distribution assumes, through length increase, the characteristics of a trapezoid distribution (Fig. 3).

\section{CONCLUSION}

By designing the measurement system for calibration of precise line scales, the Laboratory has opened the possibility of carrying out the international comparisons in the field of line scales. Thus, the Laboratory participated in the EUROMET project 882 "Calibration of line scales", L-K7. Intercomparison results of measuring the length of the $100 \mathrm{~mm}$ line scale are presented in Figure 4. Figure 4 shows that obtained results of Laboratory have no significant deviation compared to average of results of METAS, PTB and MIKES and that they have the same trend.

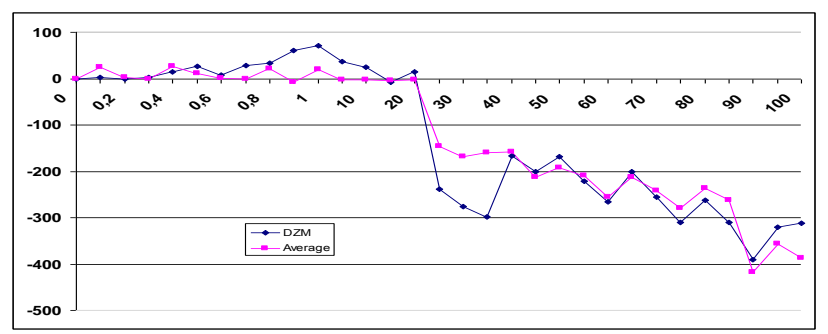

Fig. 4. Intercomparison results of measuring the length of the $100 \mathrm{~mm}$ line scale

The participation in this international comparison measurement was representing a real validation of the device and evaluated measurement uncertainty. The obtained results of this comparison will be good indication about direction of future research in a way to reduce measurement uncertainty in calibration of line scales.

\section{REFERENCES}

Bosse, H.; Flugge, J.; Koning, R. A. (2007), Method for the in situ determination of Abbe errors and their correction, Measurement science and tehnology, 18, 476-481

Družovec, M.; Aĉko B.; Godina, A.; Welzer T.(2009), Robust algorithm for determining line centre within a video positional measuring system, Optics and Laser sin Engineering 47

Beers, J. S; Penzes W. B. (1999), The NIST Length Scale Interferometer, Journal of Research of the National Institute of Standards and Technology

Medić, S.; Mudronja, V.; Runje, B. (2003), Examples of Applying Monte Carlo Simulations In The Field of Measurement Uncertainties of The Standard of Length // Proceedings of the XVII IMEKO World Congress. Cavtat, Croatia

***JCGM 101:2008, Evaluation of measurement data Supplement 1 to the "Guide to the expression of uncertainty in measurement"- Propagation of distributions using a Monte Carlo method 